\title{
Simulation and Optimization of Independent Renewable Energy Hybrid System
}

\author{
Anita Gudelj, Maja Krčum
}

In this paper the majority of research refers to the optimal configuration of hybrid system that uses renewable energy and wind energy and solar radiation in association with diesel aggregate and batteries. These independent energy systems (hybrid systems) are becoming popular due to increasing energy costs and decreasing prices of turbines and Photo-Voltaic (PV) panels. But the only drawback is that their outputs depend upon the climatic conditions. The main goal to optimization a hybrid system is necessary to obtain the configuration of the system as well as the control strategy that minimizes the total cost through the useful life of the installation to meet the desired consumption and/or the pollutant emissions. The HOGA (Hybrid Optimizations by Genetic Algorithms) program was used to simulate the system operation and calculate technical economic parameters for each configuration. The system configuration of the hybrid is derived based on the data of wind and solar radiation which are related to the southern Croatian coast, as on a theoretical annual load at an observed location. Also, technical data for components are taken from the manufacturer's specifications (datasheet). In this paper the advantages and disadvantages of commonly used types of generators (synchronous and asynchronous generators) are presented. Results show that the hybrid systems have considerable reductions in carbon emission and cost of the system.

\section{KEY WORDS}

$\sim$ Simulation

$\sim$ Optimization

$\sim$ Hybrid system

$\sim$ Renewable energy

$\sim$ HOGA

University of Split, Faculty of Maritime Studies, Split, Croatia

e-mail:anita@pfst.hr, mkrcum@pfst.hr

\section{INTRODUCTION}

Today one cannot imagine life without some form of energy such as electricity. The main source of energy has been fossil fuels, which provide $85-90 \%$ of energy. Oil is the most important with $35 \%$, and coal and natural gas are equally represented. Almost $13.5 \%$ of energy is derived from nuclear power plants, and only $9.8 \%$ of energy comes from renewable sources (Energy Markets in the European Union in 2011).

Still, in the world there are many places that have no access to electricity. Industrial plants, ACY marinas, lighthouses, mountain lodges, which are far from the power grid should also have their own stand-alone systems. Today, renewable energy is increasingly being considered as one of the key factors in the development of planet Earth.

Renewable energy sources can be divided into two main categories:

Traditional renewable energy sources like biomass and large hydropower installations, and the "new renewable energy sources" like solar energy, wind energy, geothermal energy, etc.

A renewable resource is a natural resource with the ability to reproduce through biological or natural processes and replenished with the passage of time they will never run out. This fact shows us that we should exploit renewable sources much more and that we do not have to worry about the energy after fossil fuels cease to exist. Development of renewable energy sources (especially from wind, water and sun) is important because of a couple of reasons:

- $\quad$ Renewable energy sources have major role in decreasing emissions of the carbon dioxide $\left(\mathrm{CO}_{2}\right)$ into atmosphere.

- Increased proportion of renewable energy sources enhances energetic viability of the energy system. It also helps to enhance energy delivery security by decreasing dependency on importing energetic raw materials and electrical energy. 
- It is expected that renewable energy sources will become economically competitive to conventional energy sources in a medium-term to long-term period.

Off grid renewable energy technologies satisfy energy demand directly and avoid the need for long distribution infrastructures.

A combination of different but complementary energy generation systems based on renewable energies or mixed (with a backup of Liquefied Petroleum Gas /diesel/gasoline generator), is known as a hybrid power system. Hybrid systems capture the best features of each energy resource.

Hybrid systems can provide a steady communitylevel electricity service, such as marine, village or lighthouse electrification, offering also the possibility to be upgraded through grid connection in the future. Furthermore, due to their high levels of efficiency, reliability and long term performance these systems can also be used as an effective backup solution to the public grid in case of blackouts or weak grids, and for professional energy solutions such as telecommunication stations or emergency rooms in hospitals.

When designing a hybrid system it is important to choose a good combination of components, their dimensions and to determine a good strategy to manage the system that would be reliable and economical for a long time. A large number of resources will result in large investment costs, while a system with a small number of components can result in the interruption of electricity supply in the electricity system.

Climatic conditions may affect the choice of renewable energy sources. For example, PV hybrid systems are ideal in areas with warm climates and in areas where there is large number of sunny hours.

In this paper the hybrid system is defined as a combination of components (PV generator, wind turbine, batteries, diesel generator and electrolyzes) and control variables. HOGA, the program used in this article (Dufo-López et al., 2006), simulates and optimizes the hybrid PV-Diesel system using Genetic Algorithms (GA). The program calculates the optimum system design and allows the user to evaluate the electro-economic and technical feasibility of a large number of technologies. The basic principle is to minimize the total Net Present Cost (NPC) of the system. GA researches combinations of resources which can satisfy the load with the lowest cost (Dufo-López et al., 2005).

\section{SIMULATION AND OPTIMIZATION}

The hybrid renewable energy system adopted in this paper is shown in Figure 1. It consists of wind turbines and solar PV panels. A generator (diesel or petrol) with a battery bank and an inverter are added as part of the back-up and storage system.

The main advantage of hybrid PV-Wind systems is that they make use of two different renewable sources of energy. PV panels are able to generate electricity whenever there is solar illumination, while the wind turbines are able to generate electrical power when the wind speed is greater than the cutin speed until furling speed vf is reached, at which point the machine shuts down.

The main task of designing independent power system using renewable energy resources is the correct selection of system components to satisfy the economic demands of consumers.

System components must be determined so as to:

- $\quad$ Reduce the cost of production of electricity ( $€ / \mathrm{kWh})$

- Ensure reliable meeting the needs of energy consumers.

The mathematical design problem (sizing and control of the hybrid system) involves a significant number of variables (DufoLópez et al., 2005). When the number of variables and possible solutions is very high, the classic optimization techniques are not able to obtain good results. In such design problems heuristic techniques have been successfully applied (Dufo-López et al., 2007). One of the most commonly used heuristic techniques is based on Genetic Algorithms (Goldberg, 1989). The design of the PV-Diesel system in Figure 1 has been done with HOGA. Optimization of the system will be based on the component sizing and the operational strategy. Genetic algorithm (GA) is used to evaluate both conditions in minimizing the total net present cost for optimum configuration. GA searches for the optimum system configuration which involves deciding on the mix of components that the system should contain, the size or quantity of each component, and the control strategy the system should use (see Figure 2) (Sopian et al., 2008).

\subsection{Dispatch Strategies}

During this operation of the hybrid PV/wind system different situations may appear:

1. The total current generated by the PV and wind generators is greater than the current required by the load. In this case the energy surplus is stored in the batteries and the controller puts the battery in charge condition. When the battery SOC (State of Charge) reaches the maximum value, the control system stops the charging process.

2. The total PV and wind generators' current is less than the current required by the load, the energy deficit is covered by the storage and the controller puts the battery in the discharge condition. If the battery charge decreases to its minimum level, minimum state of charge, the control system disconnects the load and we have the situation with energy deficit.

3. In case of inverter input and total power equality, the stored energy (charge of the battery) remains unchanged. 


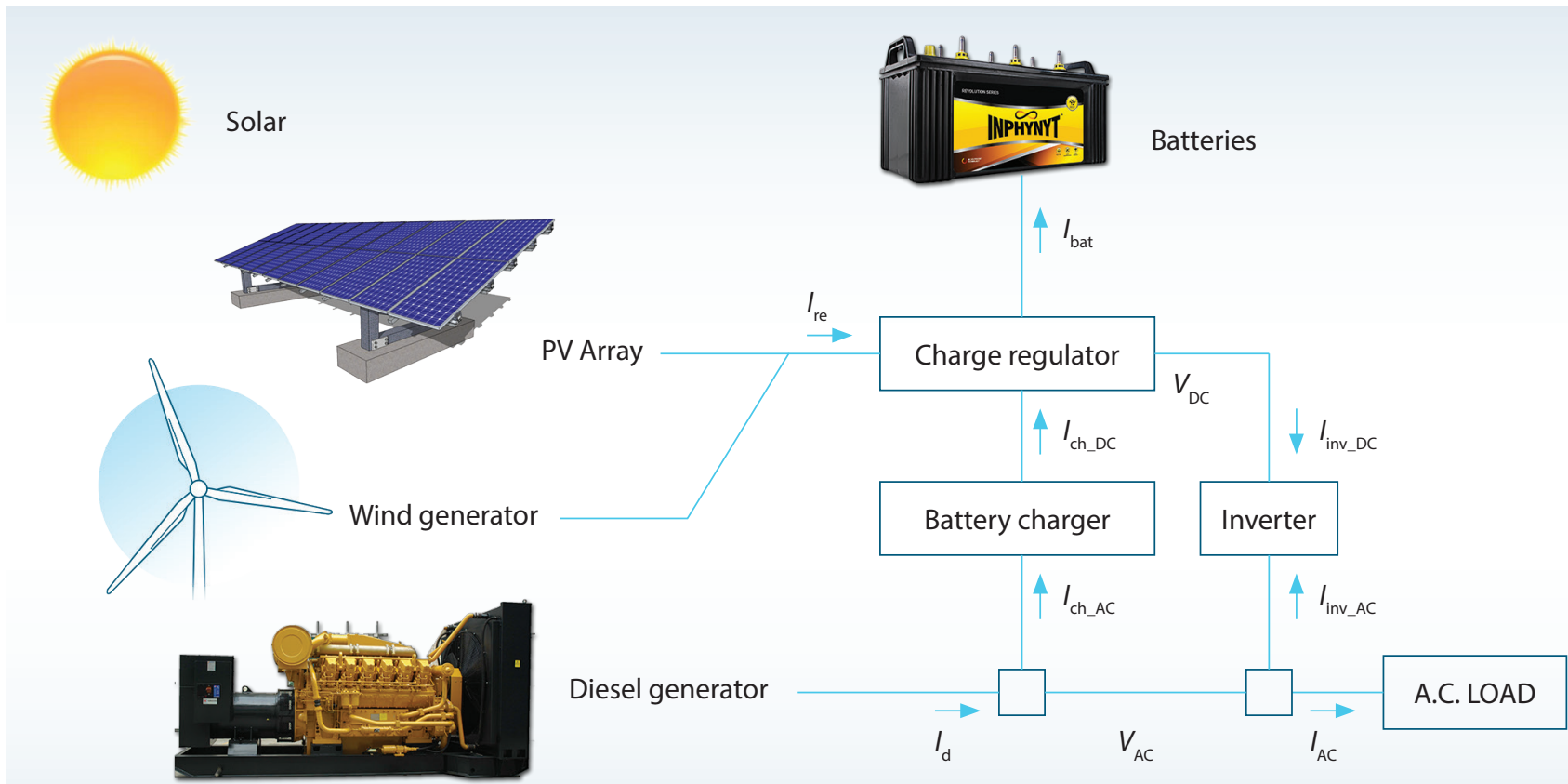

Figure 1. Renewable energy hybrid system.

\subsection{Objective Function}

The aim of this study is to achieve a stand- alone hybrid system, which should be optimally designed in terms of economic and environmental measures subject to physical and operational constraints and strategies.

In HOGA the best possible, or optimum system configuration is the one that satisfies the user-specified constraints at the objective function.

In this project the objective function is the lowest total Net Present Cost (NPC). NPC includes:

- Capital costs of the different components $C_{k}(€)$, where " $k$ " stands for each of the components of the system: the PV generator $(k=\mathrm{PV})$, the wind turbines $(k=\mathrm{W})$, the battery bank $(k=\mathrm{B})$, the inverter $(k=\mathrm{INV})$, the electrolyser $(k=\mathrm{E})$ and the diesel generator $(k=\mathrm{DG})$.

- Costs of replacing the components throughout the system lifetime, $N P C_{r_{-} k}(€)$, where " $k$ " means each of the components.

- Costs of operation and maintenance of components throughout the lifetime of the system. These costs are calculated as in (1)

$N P C_{o \& m, k}=C_{O \& M, k} * \frac{1}{C R F(i r, R)}$

where $\mathrm{R}$ is the useful lifetime of the project (here 25 years); ir is the real interest rate (here $6 \%$ ) which is a function of nominal interest rate $\left(i r_{\text {nominal }}\right)$ and annual inflation rate $\left(f_{\mathrm{r}}\right)$, defined by (Yang et al., 2008):

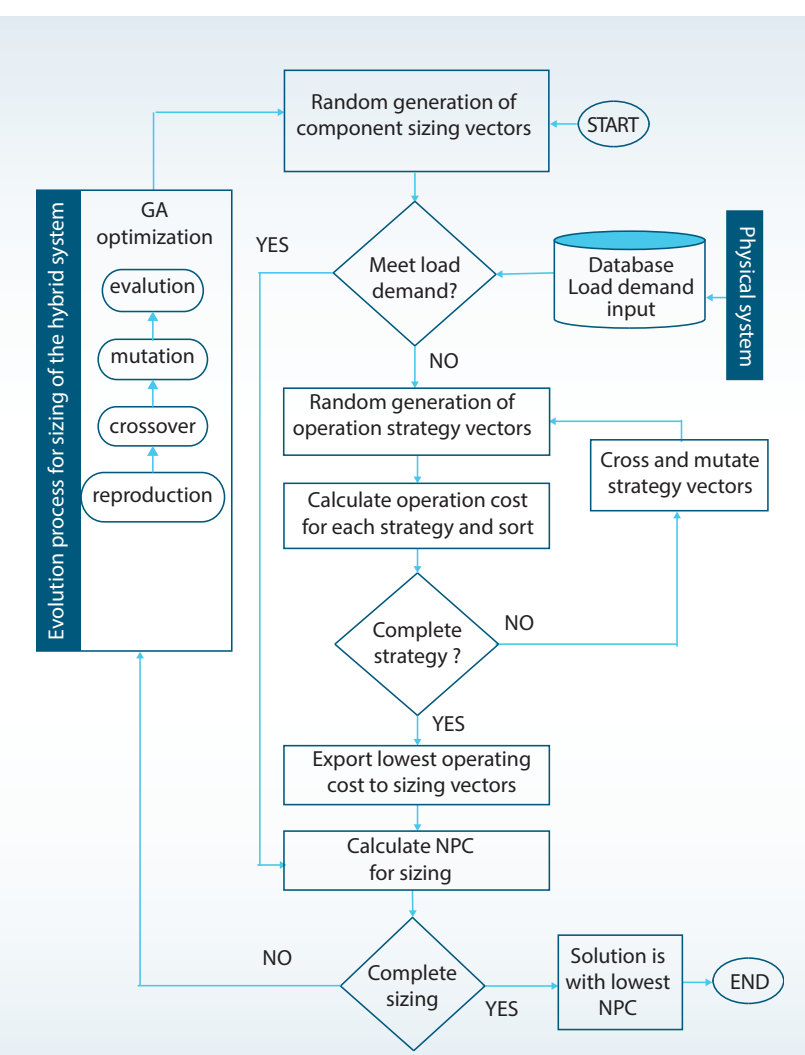

Figure 2. Flowchart of GA. 
Table 1. Average monthly daily irradiation and wind speed for the island of Hvar.

\begin{tabular}{|lccccccccccccc|}
\hline Month & Jan & Feb & Mar & Apr & May & Jun & Jul & Aug & Sep & Oct & Nov & Dec & Average \\
\hline Average daily irradiation $\left(\mathrm{kWh} / \mathrm{m}^{2}\right)$ & 1.74 & 2.61 & 3.86 & 4.77 & 6.01 & 6.85 & 7.08 & 6.05 & 4.53 & 2.84 & 1.74 & 1.42 & 4.13 \\
\hline Average wind speed $(\mathrm{m} / \mathrm{s})$ & 6.50 & 6.50 & 5.20 & 5.70 & 4.60 & 4.40 & 4.20 & 4.70 & 5.60 & 6.00 & 6.20 & 6.50 & 5.51 \\
\hline
\end{tabular}

$i r=\frac{i r_{\text {nominal }}-f r}{1+f r}$

CRF is capital recovery factor (Yang et al., 2008) which is defined as (2):

$\operatorname{CRF}(i r, R)=\frac{i r^{*}(1+i r)^{R}}{(1+i r)^{R}-1}$

- Cost of the fuel consumed throughout the lifetime of the system, $F_{c}$

Therefore, the objective function is defined as follows:

$$
N P C=\min \sum_{k}\left(C_{k}+N P C_{r, k}+N P C_{o \& m, k}+F_{c}\right)
$$

\section{CASE STUDY}

The system is located on the island of Hvar (Croatia). The average daily irradiation and average wind speed for each month for the island of Hvar is shown in Table 1 (Fowler et al., 2006). The island of Hvar is famous for its pleasant Mediterranean climate. The island is characterized by mild winters, warm summers and many hours of sunshine $(2,718$ hours a year) with the average daily solar irradiation of $4.13 \mathrm{~kW} / \mathrm{m}^{2}$. The climatic conditions on the island of Hvar are favourable for the development of solar energy due to abundant sunshine.

The minimum average annual wind speed at which it is profitable to build a wind farm is between 4 and $5 \mathrm{~m} / \mathrm{s}$. Since the mean annual wind speed for the island is $5.5 \mathrm{~m} / \mathrm{s}$ (see Table 1), it can be concluded that the island of Hvar is a favorable location for the construction of PV / wind energy system.

The system has a $48 \mathrm{~V}$ DC voltage and a $230 \mathrm{~V}$ AC voltage. The maximum allowed unmet load is $1 \%$. The study involves AC load demands as shown in Figure 3. The factors which have influence on the energy consumption of the island Hvar are number of tourists and heating season. The renewable energy supplied is based on hourly basis as the fluctuation of parameters involved in wind turbine and solar PV.

\subsection{Hybrid System Components}

The proposed hybrid renewable energy is shown in Fig. 4. Chosen PV panels that produce $1,000 \mathrm{~W}$ of power cost $5,600 €$.

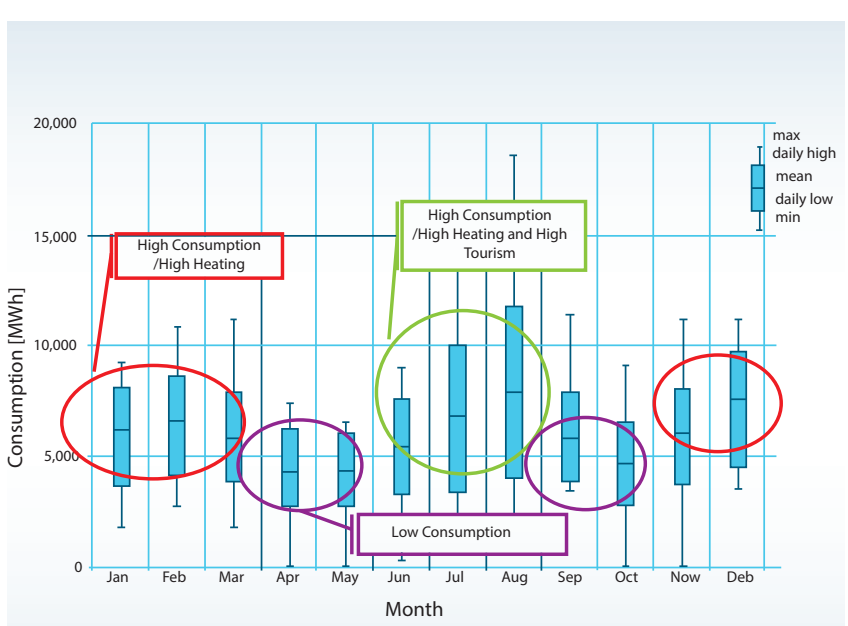

Figure 3. Monthly load data of the region.

The nominal voltage is $12 \mathrm{~V}$. The lifespan is 25 years and the annual O\&M cost is $40 € /$ year for the whole PV generator. The batteries employed in the project are specially designed for deep cyclic operation in consumer applications like the hybrid solar-wind systems. In this project there are two different battery banks. Table 2 shows their specifications. For both batteries the nominal voltage is $4 \mathrm{~V}$, floating life is 12 years and the annual O\&M cost is $20 € /$ battery bank/year. The depth of discharge (DOD) for the batteries is currently set at $80 \%$ to protect the battery from over discharge.

The minimum SOC is $40 \%$, the self-discharge coefficient is $3 \%$ monthly, and the cycles to failure depend on the depth of discharge.

The minimum number of batteries is 0 and the maximum is 32,750 . The number of batteries in series is 12 ( $48 \mathrm{~V} \mathrm{DC} / 4 \mathrm{~V}$ battery

Table 2. Specifications of the batteries.

\begin{tabular}{cccccc}
$\begin{array}{c}\text { Rated } \\
\text { capacity } \\
\text { (Ah) }\end{array}$ & $\begin{array}{c}\text { Nominal } \\
\text { voltage } \\
\text { (V) }\end{array}$ & $\begin{array}{c}\text { Charging } \\
\text { efficiency } \\
\text { (\%) }\end{array}$ & $\begin{array}{c}\text { Min state } \\
\text { of charge } \\
\text { (\%) }\end{array}$ & $\begin{array}{c}\text { Float } \\
\text { life } \\
\text { (yr) }\end{array}$ & $\begin{array}{c}\text { Cost } \\
\text { (€) }\end{array}$ \\
\hline 1,000 & 4 & 80 & 30 & 12 & 640 \\
\hline 1,900 & 4 & 80 & 40 & 12 & 700 \\
\hline
\end{tabular}


$=12$ batteries in series). These twelve battery cells are called a string. The number of strings is one of the decision variables and it will be optimized in the following process.

Five different sizes of converter $(2,3,100,8,000$ and 11,333 $\mathrm{kW}$ ) are taken in the model. The lifetime of a unit is considered to be 15 years with an efficiency of $90 \%$.

There are 4 possible different Diesel generators: 7.9; 13; 14.5 and 20 MVA. The lifespan is $150,000 \mathrm{~h}$, the minimum output power is $30 \%$ and the hourly O\&M cost ranges from $19 € / \mathrm{h}$ to $24 € / \mathrm{h}$. The Diesel fuel consumption curve $(\mathrm{l} / \mathrm{h})$ is: $0.08415 \cdot P_{\text {rated }}(k W)+0.246 \cdot P_{\text {output }}(k W) \quad$ (Bernal-Agustín, 2006; Dufo-López, 2005).

With the respect to the generator there are two types of wind turbine:

synchronous generator,

- $\quad$ asynchronous generator.

The wind turbine generator converts mechanical energy into electrical energy. Wind turbine generators are a bit unusual because the generator has to work with a power source (the wind turbine rotor) which supplies very fluctuating mechanical power (torque).

Synchronous generator:

Synchronous generator belongs to the alternating current machines. Its speed is closely connected to the frequency of the voltage and the number of poles.

$n=60 \cdot \frac{f}{p}$
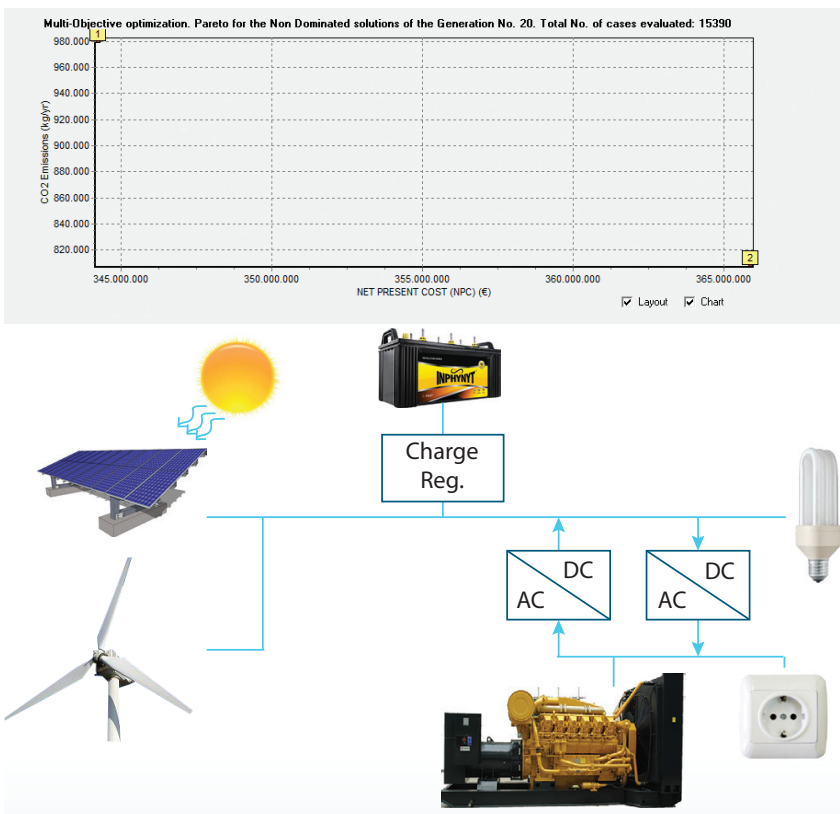

Figure 4 . The system to be simulated by HOGA. where:

$n \quad$ is the rotation speed of the rotor $[1 / \mathrm{s}]$;

$f \quad$ is frequency $[\mathrm{Hz}]$;

$p \quad$ is the number of pole pairs.

The generator can be magnetized electrically or by permanent magnets. Two types of synchronous generators have often been used in the wind turbine industry (see Figure 5): the wound rotor synchronous generator and the permanent magnet synchronous generator. Synchronous generators are usually applied when the wind speed is constant (when mounted system for rotating blades). The big advantage of synchronous generator is that they do not need a reactive magnetizing current because it can be created by using permanent magnets or with a conventional field winding as shown in the Figure 5.

It is connected to the grid using a power electronic converter which has two primary goals: to act as an energy buffer for the power fluctuations and to control the magnetization and avoid problems by remaining synchronous with the grid frequency. Wound rotor synchronous generator (WRSG) does not need any further reactive power compensation system. The speed of the synchronous generator is determined by the frequency of the rotating field and by the number of pole pairs of the rotor. PMSG has self-excitation which allows an operation at a high power factor and high efficiency. The magnetic material must be controlled by cooling system because those magnetic materials are sensible to temperature.

Asynchronous generator:

It is essentially an induction three-phase motor characterized by synchronous speed which depends on the number of poles and on the network frequency. If the mechanical torque acting on the rotor shaft is motive instead of resistant and makes the rotation speed increase and exceed the synchronous speed, the asynchronous machine stops working as a motor and starts working as a generator, thus putting electrical energy into the grid. The relative difference between the synchronous speed and the effective rotation speed is called slip (s), which is negative when the machine is operated as a generator and the slip is:

$s=\frac{n_{s}-n}{n_{s}}$

In traditional asynchronous generators with squirrel cage rotor (short-circuit rotor), the slip is about $1 \%$ so that such devices are actually considered as having constant rotation speed. The magnetizing current of the stator, which generates the rotating magnetic field in the air-gap is supplied by the grid. Besides, such generator consumes a certain amount of reactive power which shall be supplied by compensation systems such as capacitors. When a gust of wind hits a wind turbine equipped with a rotor asynchronous generator under short circuit, as the rotation speed is constant, there is a sudden variation of the 


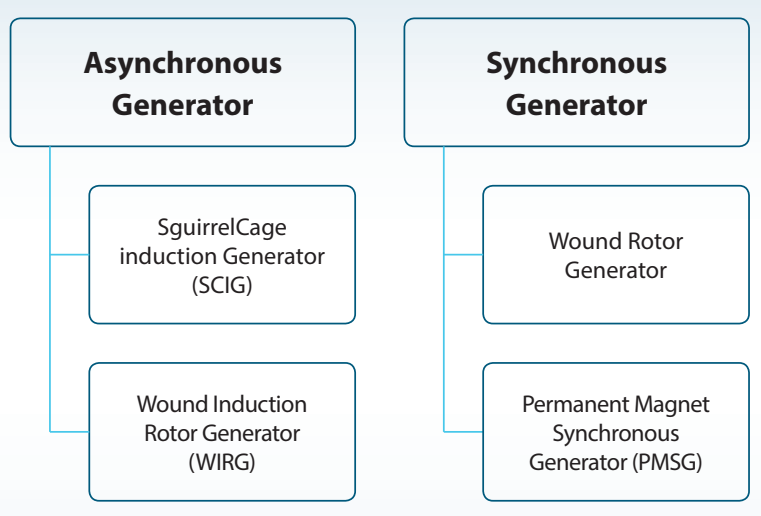

Figure 5 . The system to be simulated by HOGA.

torque and the consequent quick variation of the power output. If the short circuit power of the grid to which the wind turbine is connected is low, voltage fluctuations may occur on the electrical devices connected nearby and these fluctuations may cause malfunctioning of these devices. Moreover, it is possible to notice the quick variation of the luminous flux emitted by the lamps generating that disturbing "fluttering" known as flicker.

For this reason too, research has gone towards the development of variable speed systems which allow also the "torque pull" on the rotor to be reduced and the rotor to work at the point of maximum aerodynamic efficiency over a wide range of wind speed. Variable speed solutions realized with induction generators are obtained by interposing a frequency converter between the stator of the generator with squirrel cage rotor and the grid, or by using a wound rotor asynchronous generator in which the rotor is supplied by an independent alternating current delivered by a frequency converter: thus, the synchronous speed results to be a function of the difference between the grid frequency and the frequency of the rotor current and it is possible to reach $30 \%$ speed variation. Both synchronous and asynchronous generator are used as wind generators although the latter are most preferred. Asynchronous generators (Mohammad et al., 2008) do not require synchronization between rotor and stator rotating fields but they are characterized by smaller power range. The control techniques at the asynchronous generator are quite different from those of synchronous generators because of the absence of the excitation circuits. They are easy to maintain because they require only periodic replacement of bearings. In this analysis two wind turbines were chosen:

Scenario 1: ENERCON E-48 $810 \mathrm{~kW}$ turbines, rotor diameter $48 \mathrm{~m}$, hub height $57 \mathrm{~m}$ with price $223,000 €$ and the annual O\&M cost is about $42 €$ /year.

- $\quad$ Scenario 2: GAMESA G58 850 kW turbines, rotor diameter
$58 \mathrm{~m}$, hub height $60 \mathrm{~m}$, price $263,000 €$ and the annual O\&M cost is about $46 € /$ year. The lifetime is 20 . Maximum number of wind generators is 40 , minimum is 1 .

The Power curve of a wind turbine is an important parameter, describing the relation between the wind speed on site and the respective electrical energy output. Several manufacturers are thus providing power curves which are calculated from the results of several measured ones; the performance of these calculated power curves might be contractually guaranteed by the manufacturers. The power curve of the Enercon E-48 wind turbine is such a power curve while the power curve of the Gamesa G58 is a non-measurement based calculated power curve. During the calculation of the energy yield the power curves, given for the standard conditions of air density $=1.225 \mathrm{~kg} / \mathrm{m}^{3}$ are adapted to the air density of each individual turbine location at hub height. Figure 5 shows their components' characteristics in use. Wind turbine Gamesa G-58 generates more energy when the wind speed is between $5 \mathrm{~m} / \mathrm{s}$ and $12 \mathrm{~m} / \mathrm{s}$, and the main cause is the larger rotor diameter compared with Eracon E-48 wind turbine.

\section{RESULTS AND DISCUSSION}

HOGA provides the simulation results in terms of optimum system and optimum control strategy. The optimization results of the renewable hybrid system (Figure 4) are shown in Figures 7 and 8 . HOGA posts a list of configurations which it noted feasible for this project. Figure 7 shows the evolution of the best Total Net Present Cost found with HOGA as a function of the genetic algorithm in an optimization, where the number of generations in the genetic algorithm is 20 . The combination at the bottom in Figure 8 gives the optimum solution. It can be observed that

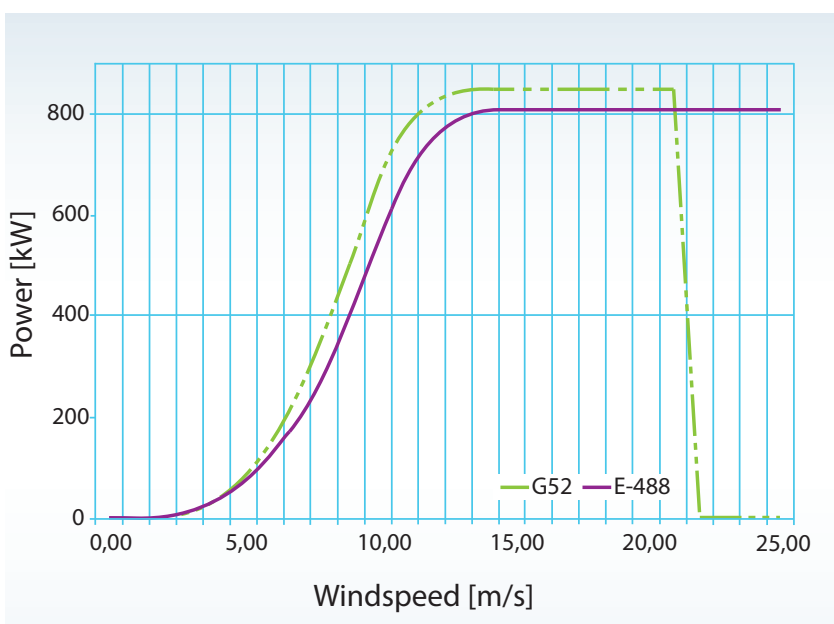

Figure 6. Power curves of the wind turbines under consideration for an air density of $=1.225 \mathrm{~kg} / \mathrm{m}^{3}$. 


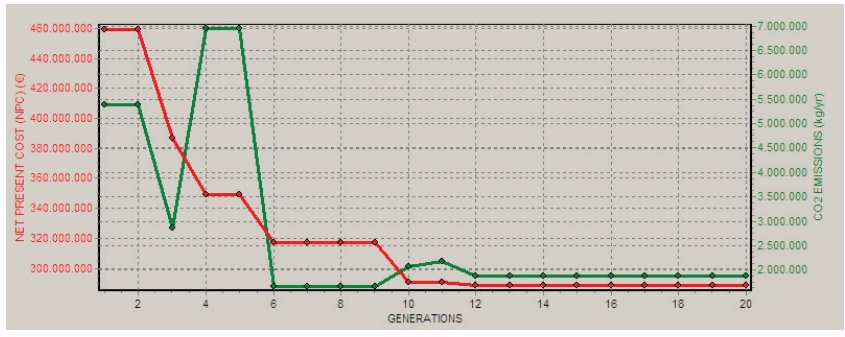

Figure 7. Evolution of the total Net Present Cost in an optimization.

the minimum Net Present Cost is $288,505,344 €$. It is the global minimum because after 20 tests with the same parameters of the algorithm a better result has not been achieved.

Figure 9 shows the best combination of components of the system from Figure 4 . This optimum configuration is composed of 4 PV Panels series $x 748$ Panels parallel with nominal power of 1,000 Wp, 12 Batteries series $\times 2,206$ Bat. parallel, $C n=1,900 \mathrm{~A} \cdot \mathrm{h}$ and Etotal $=201,39$ AC Wind Turbines with nominal power of 848,700 W at $14 \mathrm{~m} / \mathrm{s}$; AC Generator with rated power of 7,961 kVA; Inverter, $11,333,000$ VA; Battery Charge Regulator, current $=667,740,1 \mathrm{~A}$; Rectifier, 7,200,384 W. The high wind speed on the island of Hvar is the reason for the high power selected for the wind turbines in the best solution of each profile. The investment cost is 166,675,104 $€$, cost of fuel consumed by AC generator during the 1st year: $793,840 €$ and the total project cost is $288,505,344 €$. Unit cost of electrical energy per $\mathrm{kWh}$ is $0.22 €$ while the entire energy in use was satisfied by renewable energy resources.

According to the power of selected wind turbine, it can be concluded that the selected type of wind turbines are Gamesa G58 that use asynchronous generator. Only in the $6^{\text {th }}$ generation of the evolution process GA selected wind turbines with synchronous generators. A feature of such system is large emissions of $\mathrm{CO}_{2}$ gas $(2,355,076 \mathrm{~kg} \mathrm{CO} / \mathrm{yr})$ and a large amount of unmet load; $11,140.9 \mathrm{kWh} / \mathrm{yr}(0.02 \%$ of the demand load). After 20 optimizations we observed that only two optimizations obtained the local optimum solution with E-48 turbines with synchronous generators as selected for the wind generator. Therefore, the use of asynchronous generators seems more logical and economically justifiable for this region. In the period of January 10 to January 14 (winter time) in the production of energy there is a significant contribution of wind turbine (wind speed equal to $6.5 \mathrm{~m} / \mathrm{s}$ ) and the battery (see Figure 10). In this period the contribution of solar energy is minimum (smaller amount of solar radiation). In the summertime the situation is different because the solar radiation has more significant impact (see Figure 11). When the wind speed and the solar radiation are low, the load is supplied by the battery bank (night time). If batteries cannot supply the whole load, the rest will be supplied

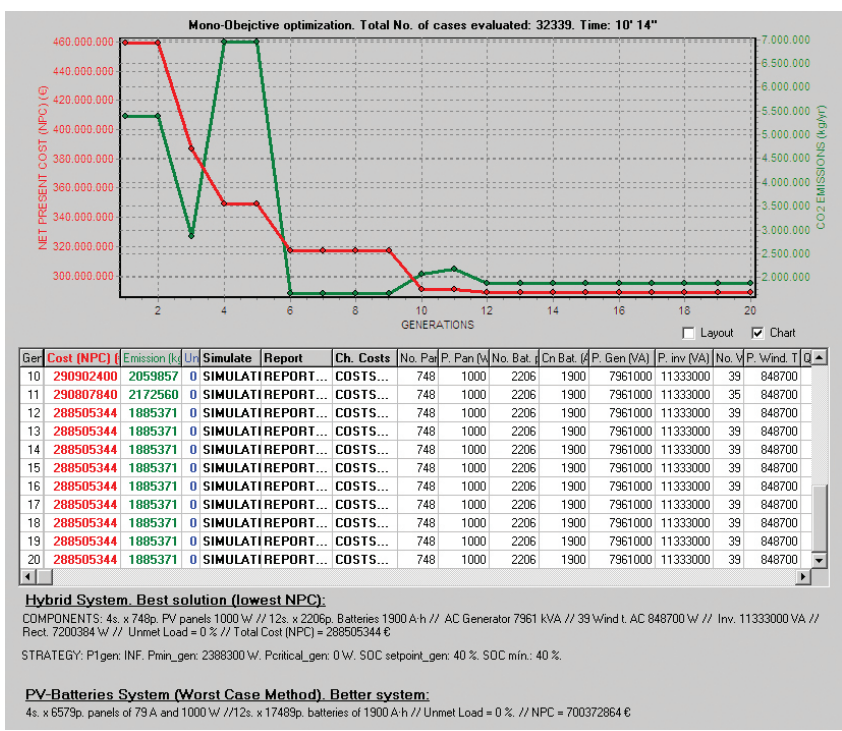

Figure 8. Optimization result of the hybrid system of renewable energy.

by the diesel generator. The surplus of energy produced by the diesel generator and the renewable energy sources (variation of the climatic data) is stored in the battery bank. The storage batteries are a key factor in a hybrid system of renewable energy, allowing to minimize the number of starting/stopping cycles of the diesel generator, which reduces the problem of its premature wear and to satisfy the request of the load in spite of renewable sources fluctuations.

\section{CONCLUSION}

The paper determined the optimum configuration of the hybrid PV-wind-battery power in terms of reliability and

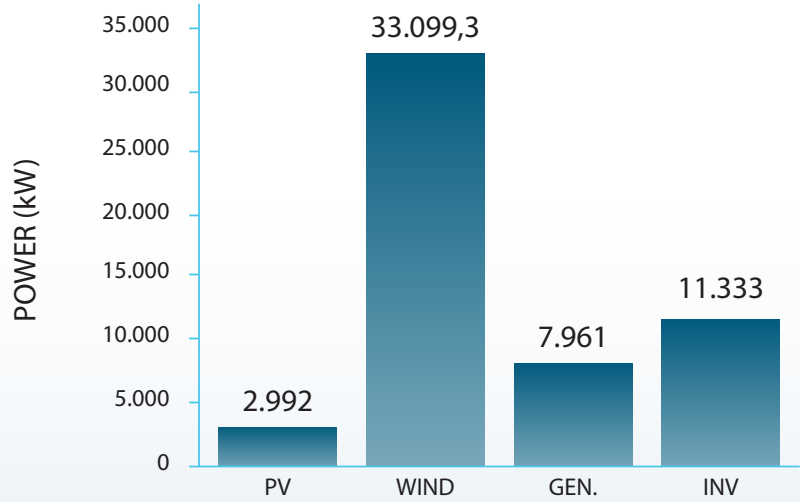

Figure 9. The components of the best system configuration. 


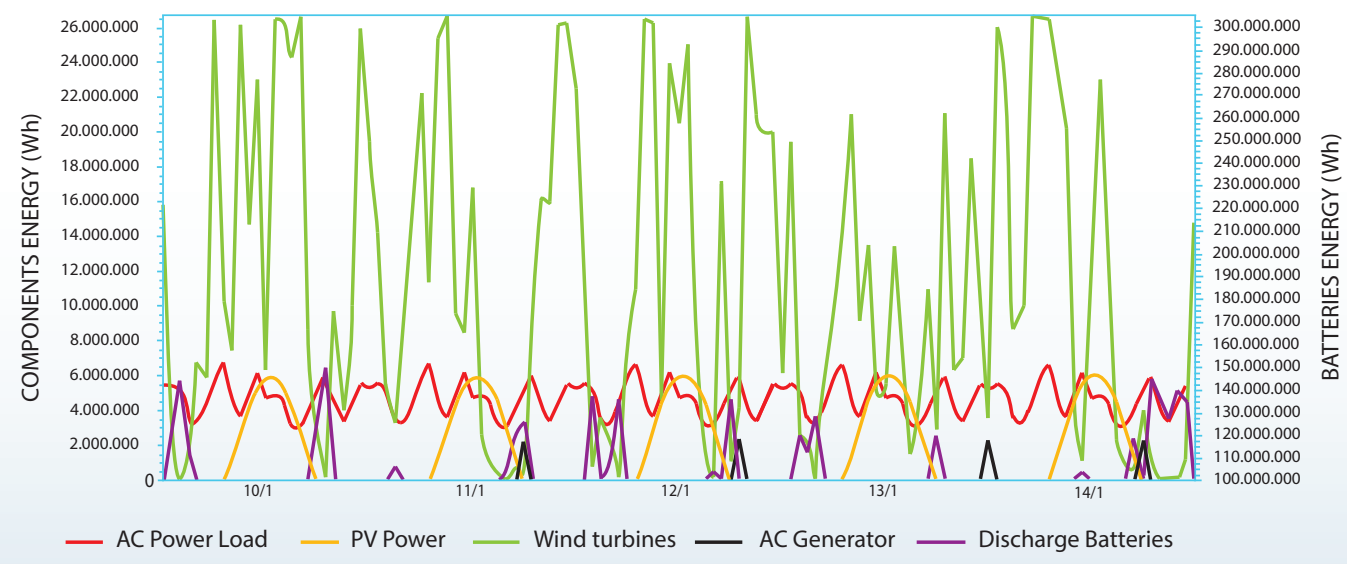

Figure 10.

The Simulation of daily values of electricity required by the load winter time. Source: Made by authors in the computer program HOGA.

Figure 11.

The Simulation of daily values of electricity required by the load - state of batteries. Source: Made by authors in the computer program HOGA.

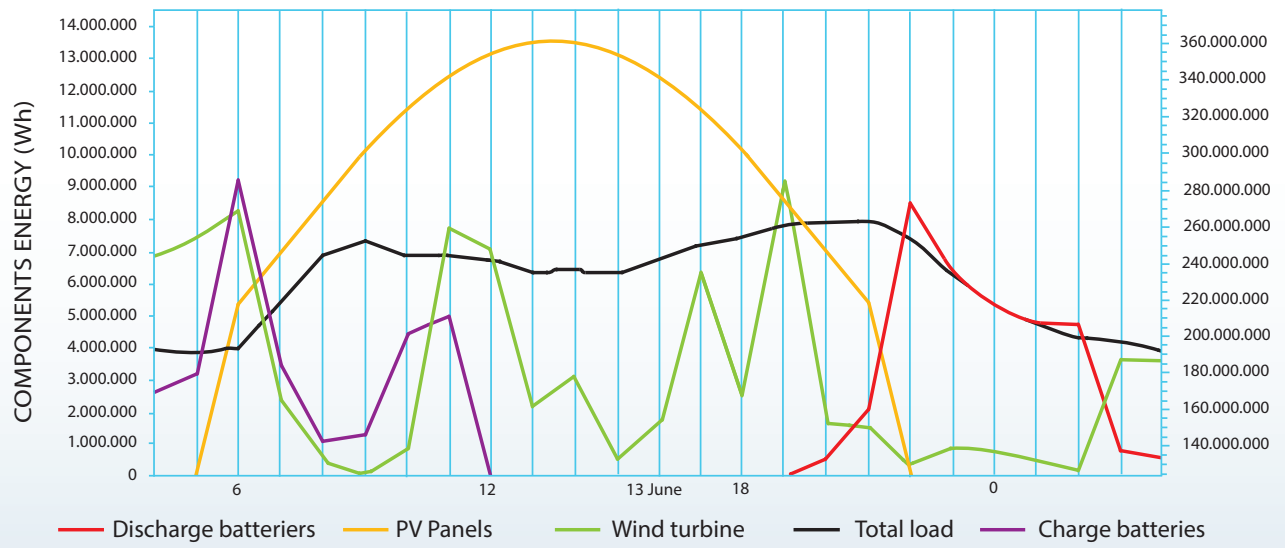

cost effectiveness. It also shows the influence of climate on the momentary load demand in the power of a system. The simulations' results prove that the combination of a diesel generator as a back-up source with the hybrid wind-PV-battery system is the best solution to guarantee the reliable supply without interruption of the load under the climatic data change.

Stand-alone systems will be able to compete with the interconnected systems in the future because of advances in technology, decreases in costs and developments in wind turbine and photovoltaic panel. The use of renewable energy sources is present in all industries. In the pre-accession period to EU membership Croatia committed for 3 X $20 \%$ to 2020: $20 \%$ higher energy efficiency, $20 \%$ of energy needs from renewable energy sources, $20 \%$ lower greenhouse gas emissions.

Shipping industry is no exception and is constantly adopting new technologies to develop along with the global economy and legislation. In subsequent papers we shall try to present some of the options for reducing greenhouse gas emissions, use of renewable energy sources and increasing energy efficiency in ship power systems.

\section{REFERENCES}

Bernal-Agustín, J. L., Dufo-López, R., Rivas-Ascaso, D. M., (2006), Design of Isolated Hybrid Systems Minimizing Costs and Pollutant Emissions, Renewable Energy, 31(14), pp. 2227-2244.,

http://dx.doi.org/10.1016/j.renene.2005.11.002

Dufo-López, R., Bernal-Agustín J. L., (2005), Design and control strategies of PVDiesel systems using genetic algorithms, Solar Energy, 79(1), pp. 33-46.,

http://dx.doi.org/10.1016/j.solener.2004.10.004

Dufo-López, R., Bernal-Agustín, J. L., Contreras, J., (2007), Optimization of Control Strategies for Stand-Alone Renewable Energy Systems with Hydrogen Storage, Renewable Energy, 32 (7), pp. 1102-1126.,

http://dx.doi.org/10.1016/j.renene.2006.04.013

Energy Markets in the European Union in 2011., (2012), Luxemburg: Publications Office of the Europan Union.

Fowler, P., Kurtalj, N., Miri, M., (2006), Energy Sustainability: Island of Hvar, Croatia-Final Report, available at: http://homerenergy.com/webcast-downloads/ Patrick_Fowler/Island_of_Hvar_Croatia_Renewable_Energy_Potential_Final_ Presentation_2006.pdf, [accessed 12 June 2012.].

Sopian, K., Zaharim, A., Ali, Y., Nopiah, Z. M., Razak, J. A., Muhammad N. S., (2008), Optimal Operational Strategy for Hybrid Renewable Energy System Using Genetic Algorithms, WSEAS Transactions on Mathematics, 7 (4), pp. 130-140. 